\title{
Hotspots and drivers of acute respiratory infection among children in Nigeria
}

\author{
T Osayomi, ${ }^{1} \mathrm{PhD}$; O B Ogbonnaiye, ${ }^{1} \mathrm{BSc}$; A E Iyanda, ${ }^{2} \mathrm{MS}$ \\ ${ }^{1}$ Department of Geography, University of Ibadan, Nigeria \\ ${ }^{2}$ Department of Geography, Texas State University, San Macros, Texas, USA
}

Corresponding author: T Osayomi (osayomi@yahoo.com)

\begin{abstract}
Background. Acute respiratory infection (ARI) is one of the leading causes of morbidity among children under five in the developing world, including Nigeria.

Objective. The study's purpose is to analyse the geographical patterns, drivers and hotspots of ARI so as to provide a guide towards ARI interventions in Nigeria.

Methods. Data for the study were obtained from the 2013 edition of the Nigerian Demographic and Health Survey (NDHS) report and the Annual Abstract of Statistics in Nigeria (2012). Spatial and statistical analyses were based on the local Getis Ord statistics and stepwise regression techniques.

Results. There was substantial spatial variation in ARI prevalence, and significant hotspots were detected in Yobe, Jigawa, Kano, Bauchi, Gombe and Taraba states. The disease hotspots were attributed to one or more of the following: Boko Haram terrorism, prevailing dustladen north-east trade winds, and frequent sandstorms in the region. Overcrowding was found to be the only significant underlying factor responsible for the observed spatial pattern $\left(\mathrm{B}=0.479 ; \mathrm{R}^{2}=0.229 ; p<0.05\right)$.

Conclusion. To combat this children's health problem, it is suggested that intervention measures including improved housing conditions and environmental sanitation should be directed at the disease hotspots.
\end{abstract}

S Afr J Child Health 2020;14(4):224-227. https://doi.org/10.7196/SAJCH.2020.v14i4.1734

Acute respiratory infection (ARI) is a disease of the respiratory system caused by viruses, fungi and bacteria, some of which include Strepotococcus pneumoniae, Haemophilus influenzae, Pneumocystis jirovecii and respiratory syncytial virus. ${ }^{[1]}$ Though preventable and treatable, this disease is the single largest infectious cause of death in children; it accounts for 16 percent of deaths among children under the age of five (U5C). In 2015, for example, 920136 children died as a result of ARI. ${ }^{[1]}$ Numerous risk factors for ARI have been indicated in the literature, which include partial/incomplete immunisation, biomass fuel use, indoor and outdoor air pollution, parental illiteracy, inadequate ventilation, cigarette/tobacco smoking, low family income and overcrowding. ${ }^{[2-5]}$ However, most of the existing studies did not consider the importance of spatial analysis and its robust capabilities in revealing patterns and predictors of diseases. ${ }^{[6]}$

In exploring factors driving the distribution of diseases and health behaviours, many studies have employed spatial techniques such as aerial photo interpretation and remote sensing (RS) for global and regional analysis of health indicators and diseases. Additionally, geographic information science (GIS) has gained currency in the field of medical geography, epidemiology and other allied disciplines. ${ }^{[6,7]}$ For example, Golding et al. ${ }^{[8]}$ used a Bayesian geostatistical analytical framework to generate a $5 \times 5 \mathrm{~km}$ grid of cells of U5C and neonatal mortality across 46 African countries. Burke et al. ${ }^{[9]}$ applied the kernel density estimator interpolation method to estimate child mortality in Africa. In a study in Ghana, Iyanda et al. ${ }^{[10]}$ used global and local spatial statistics to analyse the distribution of maternal health indicators to show the area of high and low clusters and coldspots and hotspots. Osayomi ${ }^{[11]}$ analysed the geographical pattern of diabetes mellitus in Nigeria with spatial autocorrelation and spatial regression tools. To date, limited application of geospatial techniques in the study of ARI is available, which is important for the development of location-specific intervention programmes. As a result, the present study fills that gap within the context of Sustainable Development Goals (SDGs), particularly Goal 3.2. ${ }^{[1]}$

In Nigeria, about 177000 U5C died of pneumonia, according to 2008 estimates. With this figure, Nigeria is described as the worst affected in Africa, and the country with the second-largest number of cases in the world. ${ }^{[12]}$ In terms of consequences, ARI 'is an economic burden for families and communities, contributing to the cycle of poverty. ${ }^{[13]}$ Given the public health significance, it is imperative to reduce the prevalence of ARI in Nigeria to build not only healthy lives in children but also create a sustainable future for the country. These goals, in fact, align with SDG-3 to 'Ensure healthy lives and promote well-being for all at all ages ${ }^{\text {'[14] }}$ and its sub-goal to 'end preventable deaths of newborns and $\mathrm{U} 5 \mathrm{C}$ with all countries aiming to reduce neonatal mortality to at least as low as 12 per 1000 live births and under- 5 mortality to at least as low as 25 per 1000 live births' by 2030 .

Although several studies on ARI in Nigeria exist, ${ }^{[15-18]}$ very little is known about its geographical distribution and drivers. As far as the present paper is concerned, this is a prime opportunity to investigate the geographical pattern and identify determinants and hotspots of ARI within the socio-economic, demographic, climatic and environmental contexts of Nigeria. Information arising from the spatial analysis of the disease data would hopefully be the pivot of evidence-based action plans and, in turn, ultimately improve the wellbeing of children in Nigeria. 


\section{Methods}

The two main sources of data for this study were the 2012 Annual Abstract of Statistics and the 2013 edition of the Nigeria Demographic and Health Survey (NDHS). The Annual Abstract of Statistics compiled by the National Bureau of Statistics (NBS) provides information on all facets of Nigerian society. At the same time, the NDHS is a national sample survey report that provides information on household characteristics, common childhood infections, domestic violence, female genital mutilation, maternal nutrition, sanitation facilities, etc. It is published by the National Population Commission (NPC). Other secondary sources are listed in Table 1. The choice of the selected variables is based on their recognition as possible predisposing or protective factors from the literature.

SPSS version 20 (IBM Corp., USA) was used to perform the statistical analysis while the ArcGIS 10.2 software was used to create choropleth maps and conduct spatial autocorrelation analysis - particularly the local Getis Ord analysis. The local Getis Ord technique is a local spatial autocorrelation technique used in the detection of hotspots and coldspots of a given phenomenon in geographic space. The technique searches for above- and belowaverage concentrations of a given phenomenon in space. ${ }^{[19]}$

In the present study, hotspots of ARI were those with $z$-scores $\geq 1.96$, while states with $z$-scores $<1.96$ were labelled ARI coldspots. Furthermore, stepwise regression method was used to identify the most significant factor(s) affecting the geographical distribution of ARI. Owing to the possibility of multicollinearity and redundancy

Table 1. Data sources

\begin{tabular}{llll}
\hline & Variable & Source & Year \\
\hline 1. & Rainfall & $\begin{array}{l}\text { Annual Abstract of } \\
\text { Statistics }\end{array}$ & 2012 \\
& &
\end{tabular}

2. Temperature

3. Relative humidity

4. Monthly household income

5. Cooking fuel (wood, coal, paraffin)

6. Households with generators

7. Absolute poverty

8. Motor vehicle registration

9. The literacy level of mothers (no education)

Nigerian Demographic 2013

10. Number of ARI cases

11. Houses with concrete wall and Health Survey

Population and Housing 2006 Census of the Federal Republic of Nigeria: Priority Tables Vol. 2

12. State GDP Wikipedia

13 State Human Development Index

13. Urbanisation

14. Overcrowding

United Nations 2009

Development Programme

Computed: State population divided by land area

Computed: State population divided by total number of households in each state among a set of explanatory variables, the stepwise technique extracts the best variable(s) with the most substantial effect(s) in a stepwise manner, thereby reducing the penalty of including so many variables in the model. At each step, a variable is considered for addition to (forward) or subtraction from (backward) the set of explanatory variables based on set rules. The F-Statistics allow each variable to be entered at a $90 \%$ confidence interval (CI) and removed at $95 \%$.

\section{Results \\ Spatial pattern of ARI}

There was a total of 565 cases of ARI in Nigeria in 2013. From a spatial perspective, an east-west gradient in the spatial distribution of ARI cases was clearly seen (Fig. 1). The states with the highest number of cases were Bauchi (98), Benue (54) and Yobe (53), while the least occurrences were in FCT-Abuja, Ekiti, Kogi, Edo (0) and Bayelsa (1)

As shown in Fig. 2, ARI hotspots were detected only in the northeastern region of the country - specifically Yobe, Bauchi, Gombe, Jigawa, Kano and Taraba (Fig. 2, Table 2). Interestingly, these six states are contiguous. The regression result found overcrowding to be the only significant factor $\left(B=0.479 ; R^{2}=0.229 ; F=3.225 ; p<0.05\right)$, which implies that the overcrowding index contributes $22.9 \%$ of the variation in ARI prevalence in the country. Furthermore, it is noticeable that there is a positive relationship between overcrowding and ARI prevalence (Fig. 3). This means that as overcrowding increases, the prevalence of ARI will also increase.

\section{Discussion}

The present paper has examined the geographical distribution and determinants of ARI in Nigeria and detected disease hotspots for targeted interventions. Substantial spatial variations, as already noted, were seen in ARI, with Bauchi recording the most significant number of cases. In Bauchi, $95.7 \%$ of households use wood as a fuel for cooking. ${ }^{[20]}$ This fuel source emits smoke, which is inimical to the human respiratory system and could predispose children to respiratory illnesses such as ARI.

Hotspot analysis illustrated that Yobe, Jigawa, Kano, Bauchi, Gombe and Taraba were identified as disease hotspots. The pivotal question 'Why?' arises. A combination of factors could be at work. First, the dust-laden north-east trade winds from the Sahara Desert, which bring the harmattan season into Nigeria, enter from the north-east corner. ${ }^{[21]}$ As a result, children, especially U5C, are likely to have trouble breathing as a result of unclean air, and are prone to respiratory infection. Second, the natural environment in the northern region of Nigeria is predominantly dry, and sandstorms are a common occurrence. ${ }^{[22]}$ These frequent events could make the general population, and particularly children, susceptible to respiratory illnesses. Third is ongoing Boko Haram

\section{Table 2. ARI hotspots}

\begin{tabular}{lll}
\hline State & z-score & $\boldsymbol{p}<\mathbf{0 . 0 5}$ \\
\hline Yobe & 4.060263 & 0.000049 \\
Jigawa & 3.622078 & 0.000292 \\
Kano & 2.380552 & 0.017287 \\
Bauchi & 3.376154 & 0.000735 \\
Gombe & 3.790095 & 0.000151 \\
Taraba & 3.35617 & 0.00079
\end{tabular}

$\mathrm{ARI}=$ acute respiratory infection 


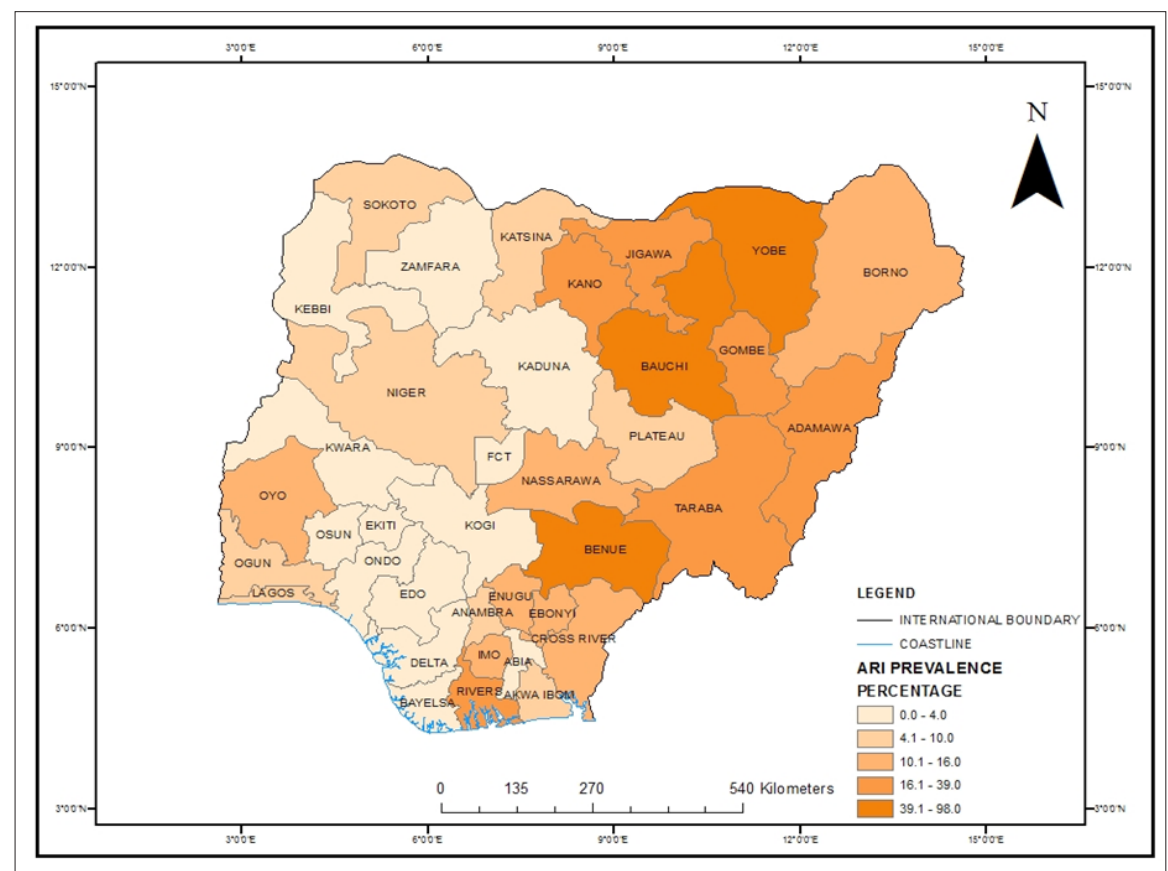

Fig. 1. Spatial distribution of ARI. (ARI = acute respiratory infection.)

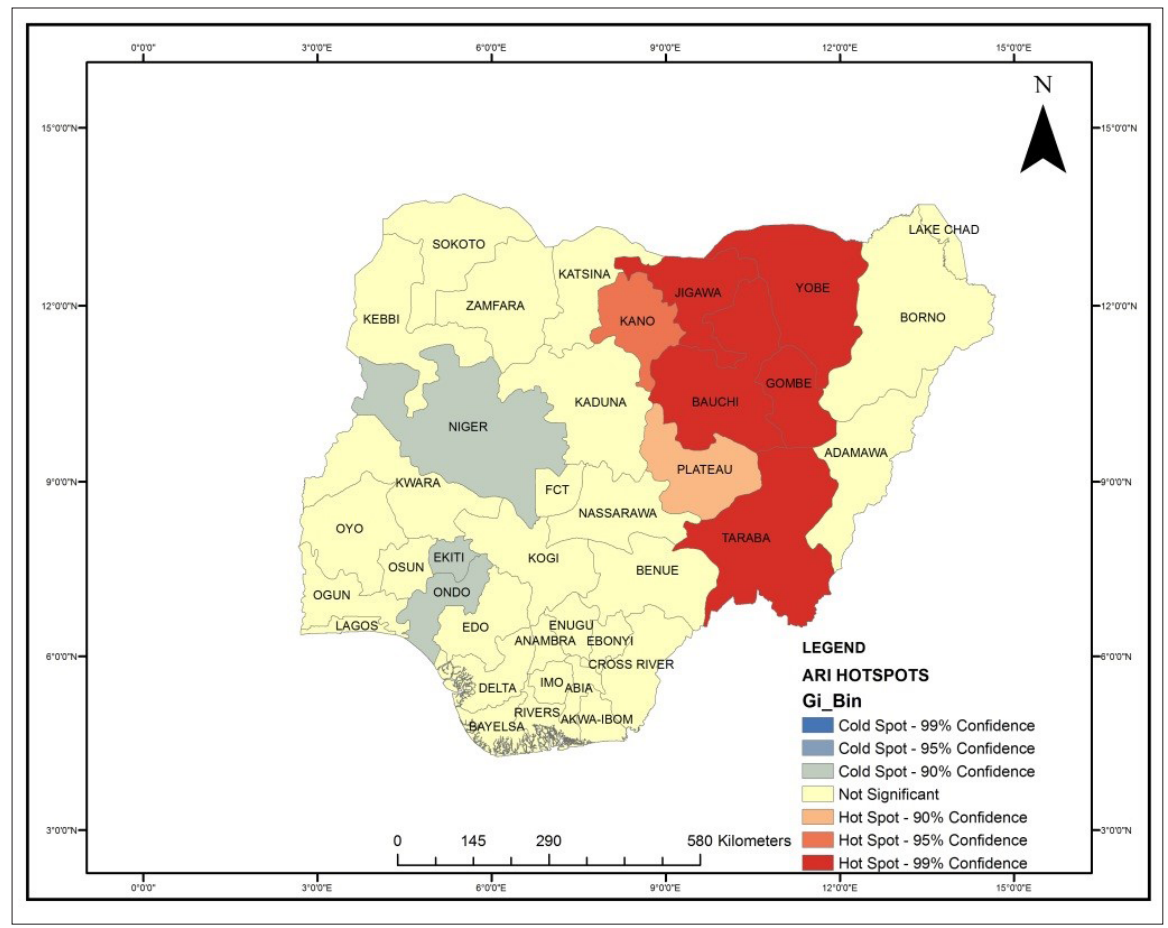

Fig. 2. ARI hotspots. (ARI = acute respiratory infection.)

insurgency in the extreme north-eastern region of the country. Apart from the adverse effect on the healthcare system, which consequently limits access to medical care during the conflict, fumes and smoke from guns and explosive devices frequently make the air unsafe for breathing. Some of the actions by Boko Haram in invading the northern communities include burning down houses, ${ }^{[23]}$ and the resulting smoke could 'living conditions, including overcrowding and poor ventilation, are related to rates of illness, child mortality and increase in negative social behaviors.' The report further stressed that the risk of disease transmission and multiple infections is exacerbated as the number of people crowded into small, poorly ventilated spaces increases. ${ }^{[24]}$

In many Nigerian urban centres are high numbers of crowded communities with little or no open space, and buildings are characterised by overcrowding, with significant numbers of persons residing in single rooms. ${ }^{[25]}$ In conditions of crowded or overcrowded housing, ARI infection would pass quickly from an infected person at very close range to other occupants or family members. As a result, children are infected with the disease when they inhale, or come into contact with, air- or surface-borne droplets from coughing, sneezing, vomiting and bleeding of infected people.

A study among Mexican children in 2015 showed that overcrowding was significantly associated with five out of seven coinfections when the viruses were rhinovirus or hR; influenza virus or IF; parainfluenza or PIF; adenovirus or hAD; and bocavirus or $\mathrm{hBoV}^{[26]}$ This finding agrees with several other studies such as those of Ujunwa et al., ${ }^{[17]}$ Prajapati et al., ${ }^{[27]}$ Taksande and Yeole, ${ }^{[28]}$ Hoge et al., ${ }^{[29]}$ and Rehman and Ishaq ${ }^{[30]}$ while it contradicts that of Myint et al., ${ }^{[31]}$ who reported a non-significant association between housing conditions and ARI among U5C in Myanmar in Gujarat, India. The strength of the present paper lies in the fact that it is probably the first significant effort to map the disease at the state level. A few limitations associated with the study include the role of overcrowding at schools, immunisation, second-hand smoke exposure, dietary patterns among children, and inadequate ventilation, which could not be taken into account owing to a dearth of data.

\section{Conclusion}

The use of geospatial techniques is novel in the study of child health problems in Nigeria. In our study, we found substantial variations in ARI among children under five years of age in Nigeria. Specifically, we identified Yobe, Jigawa, Kano, Bauchi, Gombe and Taraba as states with significant ARI hotspots. Moreover, overcrowding was the only single significant variable associated with ARI. Based on these findings, we recommend that the key child health interventions directed to ARI hotspots should be context specific and 


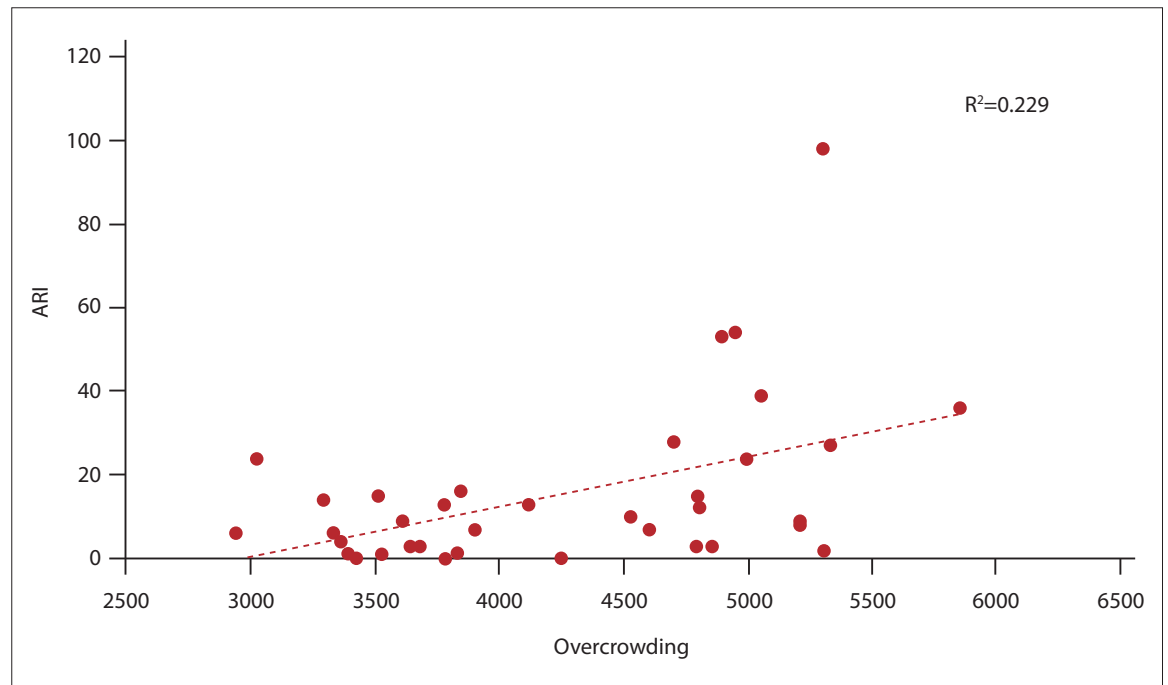

Fig. 3. Relationship between ARI and overcrowding. $(A R I=$ acute respiratory infection. $)$

culturally appropriate; housing conditions should be improved; regular environmental sanitation should be strictly enforced; public awareness be created on the causes, prevention and treatment of ARI; and postconflict health programmes for children in northeastern Nigeria be organised. Above all, this paper has illustrated that mapping the disease and identifying the contributory factors may strengthen prevention and intervention strategies.

\section{Declaration. None.}

Acknowledgements. None.

Author contributions. TO and OBO were involved in the study design, conception, analysis and interpretation of results. AEI was involved in the interpretation of results. All authors contributed to the final draft of the manuscript.

Funding. None received.

Conflicts of interest. None.

1. World Health Organization. Pneumonia: Fact Sheet. Geneva: WHO, 2016. http://www.who. int/mediacentre/factsheets/fs331/en (accessed 30 May 2017).

2. Geberetsadik A, Worku A, Berhane Y. Factors associated with acute respiratory infection in children under the age of 5 years: Evidence from the 2011 Ethiopia Demographic and Health Survey. Pediatr Health Med Ther 2015;6:9-13. https://doi.org/10.2147\%2FPHMT.S779157

3. Adesanya OA, Chiao C. A multilevel analysis of lifestyle variations in symptoms of acute respiratory infection among young children under five in Nigeria. BMC Publ Health 2016;16(1):880. https://doi.org/10.1186\%2Fs12889-016-3565-0

4. Savitha MR, Nandeeshwara SB, Kumar MP, et al. Modifiable risk factors for acute lower respiratory tract infections. Indian J Pediatr 2007;74(5):477482. https://doi.org/10.1007/s12098-007-0081-3
5. Ernest SK, Johnson AW, Mokuolu OA, et al. Acute respiratory infections in the Middle-Belt Region of Nigeria. Afr J Clin Exper Microb 2014;15(2):51-59. https://doi.org/10.4314/ajcem.v15i2.1

6. Clarke KC, McLafferty SL, Tempalski BJ. On epidemiology and geographic information systems: A review and discussion of future directions. Emerg Infect Dis 1996;2(2):85-92. https://doi.org/10.3201/eid0202.960202

7. Kistemann T, Dangendorf F, Schweikart J New perspectives on the use of Geographical Information Systems (GIS) in environmental health sciences. Int J Hyg Environ Health 2002;205(3):169-181. https://doi. org/10.1078/1438-4639-00145

8. Golding N, Burstein R, Longbottom J, et al. Mapping under-5 and neonatal mortality in Africa, 2000-15: A baseline analysis for the Sustainable Development Goals. Lancet 2017;390(10108):2171-2182.

9. Burke M, Heft-Neal S, Bendavid E. Sources of variation in under-5 mortality across subSaharan Africa: A spatial analysis. Lancet Glob Health 2016;4(12):e936-945. https://doi. org/10.1016/s2214-109x(16)30212-1

10. Iyanda AE, Oppong JR, Hamilton $\mathrm{P}$, et al. Using GIS to detect cluster and spatial disparity in maternal health indicators: A need for social health interventions. Soc Work Publ Health 2018;33(7-8):449-466. https://doi.org/10.1080/1 9371918.2018 .1543628

11. Osayomi T. The emergence of a diabetes pocket in Nigeria: The result of a spatial analysis. GeoJournal 2019;84(5):1149-1164. https:// doi.10.1007/s10708-018-9911-2

12. Black RE, Cousens S, Johnson HL, et al. Global, regional, and national causes of child mortality in 2008: A systematic analysis. Lancet 2010;375(9730):1969-1987. https://doi. org/10.1016/s0140-6736(10)60549-1

13. World Pneumonia Day. Pneumonia Facts: Nigeria - Protect Prevent Treat. 2010. stoppneumonia. org/wp-content/uploads/.../Fact-sheet-NigeriaSeptember-2010-1.pdf (accessed 30 May 2019).

14. United Nations Sustainable Development Goals: 2016 http://www.un.org/sustainabledevelopment/sustainable-development-goals (accessed 30 May 2017).

15. Ahmed PA, Yusuf KK, Dawodu A Childhood acute lower respiratory tract infections in Northern Nigeria: At risk factors. Niger J Paed 2015;42(3):188193. https://doi.org/10.4314/njp.v42i3.3 org/10.1016/s140-6736/(17)31758-0
16. Ibraheem RM, Johnson AB, Abdulkarim AA, et al. Serum zinc levels in hospitalised children with acute lower respiratory infections in the north-central region of Nigeria. Afr Health Sci 2014;14(1):136-142. https://doi. org/10.4314\%2Fahs.v14i1.21

17. Ujunwa FA, Ezeonu CT. Risk factors for acute respiratory tract infections in under-five children in Enugu, Southeast Nigeria. Ann Med Health Sci Res 2014;4(1):95-99. https://doi. org/10.4103/2141-9248.126610

18. Yilgwan CS, John C, Abok II, et al. Pattern of acute respiratory infections in hospitalised children under five years of age in Jos Nigeria. Niger J Paed 2013;40(2):150-153.

19. Getis A, Ord J. Local spatial autocorrelation statistics: Distributional issues and an application. Geographical Analysis 1995;27:287-306.

20. National Bureau of Statistics. Annual Abstract of Statistics. 2012. National Bureau of Statistics Abuja.

21. Okeahialam BN. Article commentary: The cold dusty harmattan: A season of anguish for cardiologists and patients. Environ Health Insights 2016;10:143-146. https://doi. org/10.4137\%2FEHI.S38350

22. Ologunorisa TE, Tamuno TT. Spatial and seasonal variations of sandstorms over Nigeria. Theoretical and Applied Climatology 2003;75(1-2):55-63. https://doi.org/10.1007/s00704-002-0712-6

23. Sampson IT. The dilemmas of counterbokoharamism: Debating state responses to Boko Haram terrorism in northern Nigeria. Security J 2016;29(2):122-146. https://doi.org/10.1057/ sj. 2013.2

24. United Nations Human Settlements Programme. The state of the world's cities report 2006/2007: 30 years of shaping the habitat agenda. 2007. https://sustainabledevelopment.un.org/content/ documents/11292101_alt.pdf (accessed 4 April 2020).

25. Lanrewaju AF. Urbanisation, housing quality and environmental degeneration in Nigeria. Geog Reg Plan 2012;5(16):422-429. https://doi. org/10.5897/JGRP12.060

26. Diaz J, Morales-Romero J, Pérez-Gil G, et al. Viral coinfection in acute respiratory infection in Mexican children treated by the emergency service: A cross-sectional study. Ital J Pediatr 2015;41(1):1-8. https://doi.org/10.1186/s13052015-0133-7

27. Prajapati B, Talsania N, Sonaliya KN. A study on prevalence of acute respiratory tract infections (ARI) in under five children in urban and rural communities of Ahmedabad District, Gujarat. National J Comm Med 2011;2(2):255-259.

28. Taksande AM, Yeole M. Risk factor of acute respiratory infection (ARI) in under-fives in a rural hospital of Central India. J Pediatr Neonatal Individualised Med 2016;5(1):e050105. https:// doi.org/10.7363/050105

29. Hoge CW, Reichler MR, Dominguez EA, et al. An epidemic of pneumococcal disease in an overcrowded, inadequately ventilated jail. $\mathrm{N}$ Engl J Med 1994;331(10):643-648. https://doi. org/10.1056/nejm199409083311004

30. Rehman MU, Ishaq M. Prevalence of acute respiratory infections (ARI) and its risk factors in under five children in urban and rural areas of Matta, District Swat. Int J Infect Dis 2016;73:230. https://doi.org/10.1016/j.ijid.2018.04.3937.

31. Myint SL, KhinThet W, Khaymar M, et al Estimation of acute diarrhea and acute respiratory infections among children under five years who lived in a peri-urban environment of Myanmar. OSIR J 2016;6(4):13-18. 